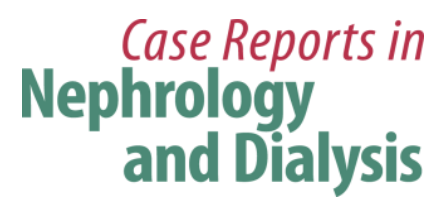

Case Rep Nephrol Dial 2016;6:128-132

DOI: $10.1159 / 000452299$

Publisnea onine: November 1, 2016

(c) 2016 The Author(s)
Published by S. Karger AG, Basel
www.karger.com/cnd

Karger

open access

This article is licensed under the Creative Commons Attribution-NonCommercial 4.0 International License (CC BY-NC) (http://www.karger.com/Services/OpenAccessLicense). Usage and distribution for commercial purposes requires written permission.

\title{
Giant true Brachial Artery Aneurysm after Hemodialysis Fistula Closure in a Renal Transplant Patient
}

\author{
Doriana Ferrara $^{a} \quad$ Michele Di Filippo $^{a} \quad$ Flavia Spalla $^{a}$ \\ Anna Maria Giribono ${ }^{a}$ Emanuela Viviani $^{a} \quad$ Annamaria Santagata $^{a}$ \\ Umberto Bracale $^{b} \quad$ Michele Santangelo $^{c} \quad$ Luca del Guercio $^{a}$ \\ Umberto Marcello Bracale ${ }^{a}$ \\ ${ }^{a}$ Operative Unit of Vascular and Endovascular Surgery, University Federico II of Naples, \\ Naples, Italy; ${ }^{b}$ Operative Unit of General Surgery, University Federico II of Naples, \\ Naples, Italy; ' Operative Unit of General Surgery \& Transplants, University Federico II of \\ Naples, Naples, Italy
}

\section{Keywords}

Brachial artery · Aneurysm · Arteriovenous fistula · Dialysis · Renal transplantation

\begin{abstract}
The usual manifestation of brachial artery aneurysms is the incidental finding of a swelling of the arm, combined with paresthesia or pain in some cases. The etiology is often traumatic or secondary to drug abuse. Pathophysiology of brachial artery dilation in these cases is not completely clear. We herein describe a case of a 61-year-old male presenting with a giant, painful, pulsatile mass on his left arm. He was submitted to a cadaveric kidney transplant in 2005. He had a functioning arteriovenous fistula (AVF) on his right arm, and a spontaneously thrombosed radiocephalic AVF on his left arm. The aneurysm was surgically resected, sparing the median nerve that was totally entrapped and an inverted segment of the basilic vein interposed. At the follow-up, the patient did not present neurological or ischemic disturbs, and the vein graft maintained its patency.




\section{Case Reports in Nephrology and Dialysis}

\begin{tabular}{l|l}
\hline DOI: 10.1159/000452299 & (c) 2016 The Author(s). Published by S. Karger AG, Basel \\
\hline
\end{tabular} www.karger.com/cnd

Ferrara et al.: Giant true Brachial Artery Aneurysm after Hemodialysis Fistula Closure in a Renal Transplant Patient

\section{Introduction}

Brachial artery aneurysm (BAA) is a rare pathological arterial dilation that can lead to severe complications such as thrombosis and thromboembolic events. To date, etiology is not well defined, but one of the observed causes is the presence of a functioning or surgically closed arteriovenous fistula (AVF) for hemodialysis [1]. In this paper, we describe the surgical treatment of a giant BAA on the left arm several years after spontaneous closure of an ipsilateral radiocephalic hemodialysis AVF.

\section{Case Presentation}

A 61-year-old male was admitted to our department complaining of pain and paresthesia in the left upper limb associated with massive swelling. He was a heavy smoker and had a past medical history remarkable for hypertension and bilateral polycystic kidney disease. The patient started hemodialysis in 2003 from a distal radiocephalic AVF on the left arm. After spontaneous fistula thrombosis 1 year later, a new radiocephalic AVF for hemodialysis was created on the right arm. In 2005, he received a successful cadaveric kidney transplant in the right iliac fossa and since then had been administered with immunosuppressive drugs (cyclosporine $20 \mathrm{mg}$ and mycophenolate mofetil 2,000 mg daily) and corticosteroids (methylprednisolone $4 \mathrm{mg}$ daily) to avoid renal rejection. The patient lamented a small swelling of the left arm persisting for 2 years, which in the last 4 months went through an important increase in size, associated with mild paresthetic symptoms.

The patient's past medical history was negative for injective drug abuse, upper-limb trauma, and brachial artery access for endovascular procedures.

On physical examination, he had a left arm circumference of $41 \mathrm{~cm}$, compared to the contralateral arm of $26 \mathrm{~cm}$, with a pulsing ovoid swelling on the medial aspect, $3 \mathrm{~cm}$ above the medial epicondyle at the level of the armpit (Fig. 1).

The mass resulted tight, pulsatile and incompressible, and painful on palpation along with mild distal edema. Bilaterally, the supraclavicular and axillary lymph nodes were not palpable. The right and left radial and ulnar pulses were both palpable. An ultrasound duplex scan of the left upper-limb arterial system revealed a giant true aneurysm of the brachial artery in presence of parietal thrombosis with turbulent flow seen along the vessel.

The patient underwent surgical treatment under general anesthesia. He was placed in the supine position with abducted left upper limb. An incision was made over the axilla, and the BAA was isolated with proximal and distal brachial artery control.

The aneurysm, entrapping the median nerve, was resected, and an interposition reversed basilic vein graft was used to restore the blood flow in the arm (Fig. 2). Intraoperative ultrasound duplex scan examination of the vein graft showed patency and good functioning. The limb was warm with good capillary filling, the patient had relief of pain and numbness, and the radial and ulnar arteries were palpable distally. The patient was discharged 2 days after the operation, not presenting local or systemic complications.

Histological findings on the surgical sample submitted to hematoxylin and eosin stain showed atherosclerotic wall degeneration with fibrous and calcific tissue and intraluminal thrombus (Fig. 3).

The 1-month follow-up clinical examination revealed no pain or neurological deficit, but radial and ulnar pulses were still present. An ultrasound duplex scan showed patency of the vein graft. 


\section{Case Reports in Nephrology and Dialysis}

Ferrara et al.: Giant true Brachial Artery Aneurysm after Hemodialysis Fistula Closure in a Renal Transplant Patient

\section{Discussion}

BAAs are uncommon [2-4]; usually, they are caused by trauma, including iatrogenic ones, and drug abuse [5].

The usual manifestation of BAAs is an accidental finding of a pulsatile, painless, and asymptomatic mass. Complications include thrombosis of the sac, thromboembolic events with ischemia, and disruption causing profuse bleeding [6].

AVFs determine the increase in the brachial and radial artery blood flow rate. Nitric oxide and reactive oxygen species released by the endothelium combine to produce peroxynitrite that upregulates matrix metalloproteinase production. This process results in a damage of the internal elastic lamina of the arterial wall followed by aneurysm formation, even after the AVF closure [1].

Long-term steroid and immunosuppressive therapy has been reported as an accelerating factor of aneurysm development and rupture $[7,8]$. Although the natural history of BAA is not well defined, management of complications such as hemorrhage, extremity venous edema, and neurological compression due to aneurysm enlargement is mandatory because of their life-threatening or disabling nature [4]. Duplex scan ultrasonography allows easy BAA detection combining accurate downstream vascularization study. Even though some authors propose digital subtraction angiography as diagnostic of choice, computed tomography angiography can offer detailed information about the extension of the aneurysm and its relationship with adjacent structures such as nerves, as in our case [9].

Therapeutic options for true BAAs include the conservative treatment and either conventional or endovascular repair. As Kordzadeh et al. [10] describe in a recent review of 23 case reports from 1951 to 2014, open surgery is the treatment of choice for BAAs, with a preference of aneurysmectomy with interposition of the vein graft compared to polytetrafluoroethylene, with mean patency rates of 12 versus 6 months.

When approaching giant BAAs with open surgery and a direct repair with an end-to-end arterial anastomosis is not feasible, vein grafts are preferred to the implantation of prosthetic material; usually the great saphenous vein is the conduit of choice, followed by the upperlimb veins, as suggested by Chemla et al. [11]. In the case presented, the patient had a moderate chronic venous insufficiency bilaterally, which did not allow using the saphenous vein for the graft. Therefore, the ipsilateral basilic vein was chosen. Only recently, Fendri et al. [12] described a successful case of arterial transposition using a superficial femoral artery to replace a BAA in complete absence of vein conduits for bypass or the possibility to position a prosthetic graft.

Another reason why the open repair was chosen was the risk of contrast-induced nephropathy. Contrast-induced nephropathy is characterized by the development of acute kidney injury after the administration of intravascular iodinated radiocontrast media, and the incidence ranges from 3 to $30 \%$, depending on the preexisting risk factors, with higher incidence noted in the presence of diabetes mellitus, chronic kidney disease, and older age. The patient presented a mild alteration of the renal function (serum creatinine: $1.3 \mathrm{mg} / \mathrm{dL}$ and estimated glomerular filtration rate: $68 \mathrm{~mL} / \mathrm{min}$ ), and therefore an endovascular approach could have been an excessive risk for the patient. For the same reason, no contrastenhanced computed tomography angiography scan was performed, since the ultrasound duplex scan had been sufficient in achieving preoperative information $[13,14]$.

Although the endovascular techniques are constantly improving and widening their therapeutic possibilities on our experience, an open repair is at the moment the safest and most successful treatment for BAAs after AVFs for hemodialysis. 


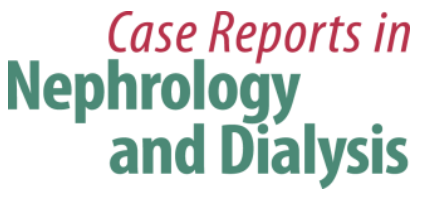

Case Rep Nephrol Dial 2016;6:128-132 DOI: $10.1159 / 000452299$

(C) 2016 The Author(s). Published by S. Karger AG, Basel www.karger.com/cnd

Ferrara et al.: Giant true Brachial Artery Aneurysm after Hemodialysis Fistula Closure in a Renal Transplant Patient

\section{Conclusion}

Although BAA is a rare condition, the treatment is mandatory in order to avoid severe complications such as embolic or thrombotic events related to the risk of hand vascularization damaging or neurologic deficits due to nerve entrapment. Hemodynamic alterations in the brachial artery blood stream caused by hemodialysis AVF and its closure seem to be one of the major etiological factors of aneurysm growth. Open surgical repair with aneurysm resection and vein or prosthetic graft substitution offers good results in terms of patency and perioperative morbidity.

\section{Statement of Ethics}

Consent for publication was obtained from the patient.

\section{Disclosure Statement}

The authors have no conflicts of interest to declare.

\section{References}

1 Basile C, Antonelli M, Libutti P, Teutonico A, Casucci F, Lomonte C: Is there a link between the late occurrence of a brachial artery aneurysm and the ligation of an arteriovenous fistula? Semin Dial 2011;24:341-342.

2 Gray RJ, Stone WM, Fowl RJ, Cherry KJ, Bower TC: Management of true aneurysms distal to the axillary artery. J Vasc Surg 1998;28:606-610.

-3 Tetik O, Ozcem B, Calli AO, Gurbuz A: True brachial artery aneurysm. Tex Heart Inst J 2010;37:618-619.

4 Schunn CD, Sullivan TM: Brachial arteriomegaly and true aneurysmal degeneration: case report and literature review. Vasc Med 2002;7:25-27.

-5 Hudorović N, Lovricević I, Brkić P, Ahel Z, Vicić-Hudorović V: Renal replacement therapies after abdominal aortic aneurysm repair - a review. Acta Clin Croat 2011;50:403-414.

-6 Dinoto E, Bracale UM, Vitale G, Cacciatore M, Pecoraro F, Cassaro L, Lo Monte AI, Bajardi G: Late, giant brachial artery aneurysm following hemodialysis fistula ligation in a renal transplant patient: case report and literature review. Gen Thorac Cardiovasc Surg 2012;60:768-770.

7 Sato 0, Atsuhiko T, Tetsuro M, Takayama Y: Aortic aneurysm in patients with autoimmune disorders treated with corticosteroids. Eur J Vasc Endovasc Surg 1995;10:366-369.

8 Reilly JM, Savage EB, Brophy CM, Tilson MD: Hydrocortisone rapidly induces aortic rupture in a genetically susceptible mouse. Arch Surg 1990;125:707-709.

-9 Yetkin U, Gurbuz A: Post-traumatic pseudoaneurysm of the brachial artery and its surgical treatment. Tex Heart Inst J 2003;30:293-297.

10 Kordzadeh A, D’Espiney BRM, Ahmad AS, Hanif MA, Panayiotopoulos YP: Donor artery aneurysm formation following the ligation of haemodialysis arteriovenous fistula: a systematic review and case reports. J Vasc Access 2015;16:5-12.

-11 Chemla E, Nortley M, Morsy M: Brachial artery aneurysms associated with arteriovenous access for hemodyalisis. Semin Dial 2010;23:440-444.

-12 Fendri J, Palcau L, Camelierie L, Coffin O, Felisaz A, Gouicem D, Dufranc J, Laneelle D, Berger L: True brachial artery aneurysm after arteriovenous fistula for hemodyalisis: five cases and literature review. Ann Vasc Surg 2016, Epub ahead of print.

13 Caruso M, Balasus F, Incalcaterra E, Ruggieri A, Evola S, Fattouch K, Bracale UM, Amodio E, Novo G, Andolina G, Novo S: Contrast-induced nephropathy after percutaneous coronary intervention in simple lesions: risk factors and incidence are affected by the definition utilized. Intern Med 2011;50:983-989.

$>14$ Haider M, Yessayan L, Venkat KK, Goggins M, Patel A, Karthikeyan V: Incidence of contrast-induced nephropathy in kidney transplant recipients. Transplant Proc 2015;47:379-383. 


\section{Case Reports in Nephrology and Dialysis}

Case Rep Nephrol Dial 2016;6:128-132

(c) 2016 The Author(s). Published by S. Karger AG, Basel www.karger.com/cnd

Ferrara et al.: Giant true Brachial Artery Aneurysm after Hemodialysis Fistula Closure in Renal Transplant Patient

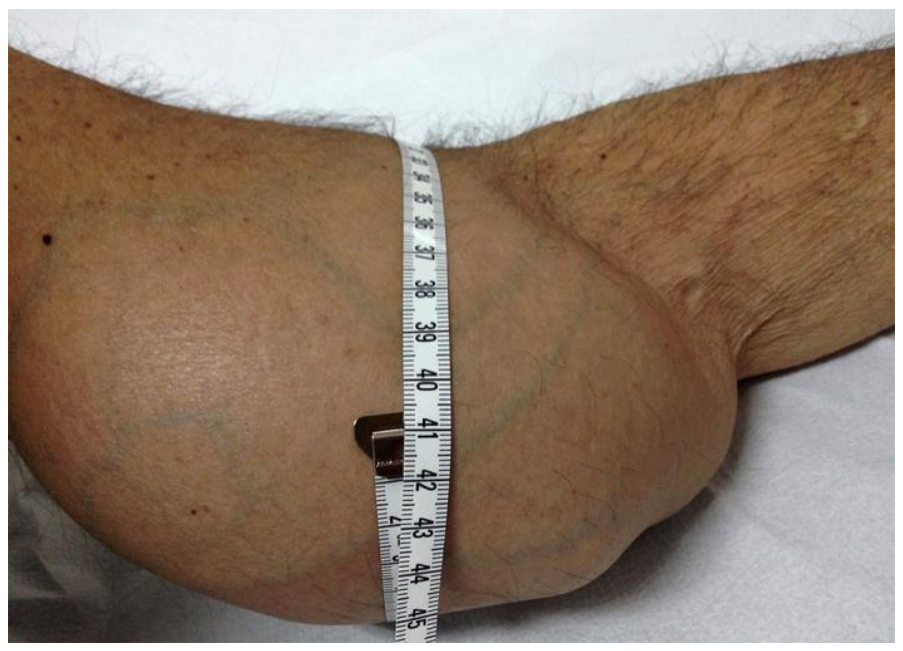

Fig. 1. Preoperative photograph of the patient's left arm.
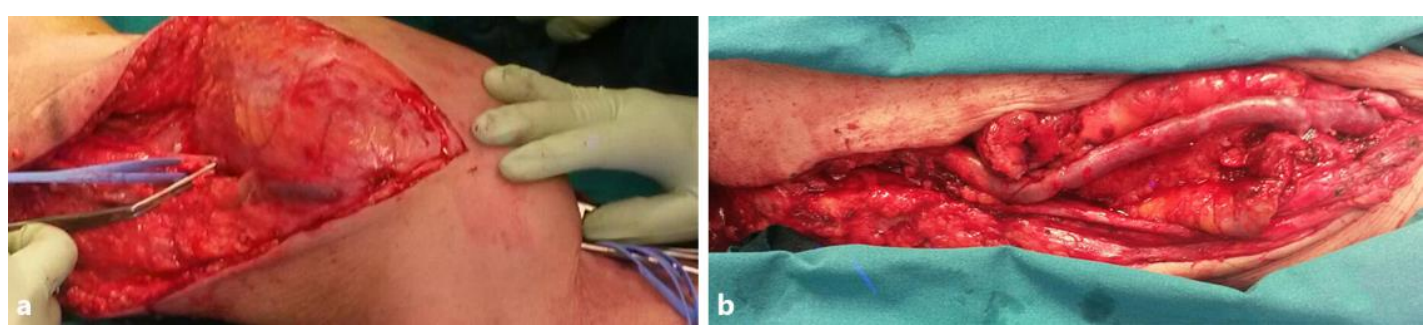

Fig. 2. Intraoperative images showing the isolated brachial artery aneurysm (a) and interposition basilic vein graft after resection (b).
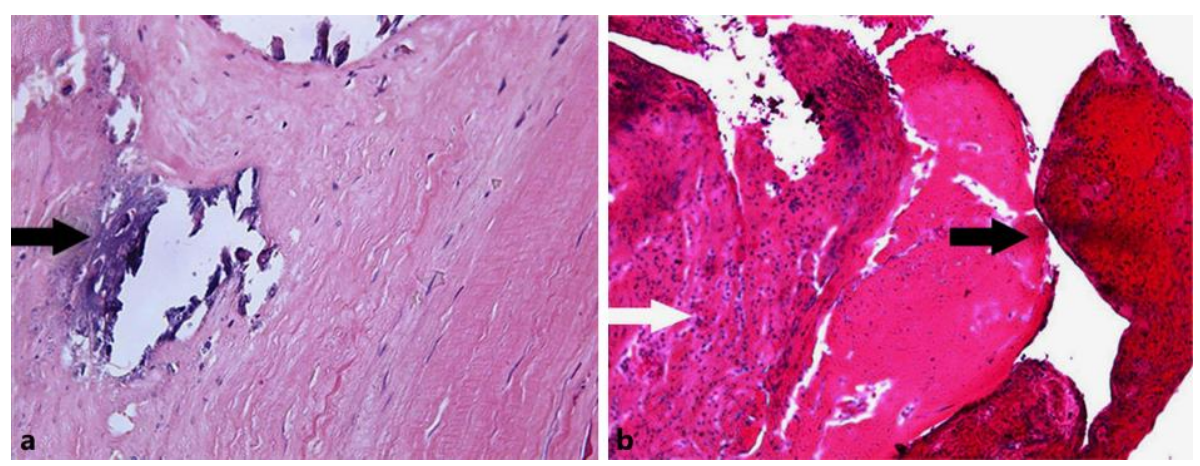

Fig. 3. Aneurysm specimen showing calcifications of the arterial wall (black arrow; a) and inflammatory cell infiltration (white arrow) as well as intraluminal thrombosis (black arrow; b). 